\title{
On the generality of the contingent orienting hypothesis
}

\author{
Su-Ling Yeh *, Hsin-I Liao \\ National Taiwan University, Department of Psychology, No. 1, Sec. 4, Roosevelt Rd, Taipei 10617, Taiwan
}

\section{A R T I C L E I N F O}

\section{Article history:}

Received 19 December 2007

Received in revised form 25 May 2008

Accepted 26 May 2008

Available online 9 July 2008

\section{PsycINFO classification: \\ 2323 \\ 2346}

Keywords:

Attentional capture

Spatial cueing

Singleton detection mode

Feature search

Salience

Set size

\begin{abstract}
A B S T R A C T
The contingent-orienting hypothesis states that attentional capture by a task-irrelevant stimulus is contingent on whether that stimulus shares a feature property that is critical to the task at hand [Folk, C. L., Remington, R. W., \& Johnston, J. C. (1992). Involuntary covert orienting is contingent on attentional control settings. Journal of Experimental Psychology: Human Perception and Performance, 18, 1030-1044]. Studies supporting this hypothesis have mostly used set size four displays throughout the experiment and thus constrict its ecological validity, since conclusions drawn from experiments using fixed set-size displays may not be generalized to other conditions with different set sizes. We used a spatial cueing paradigm in which a non-informative onset or color cue preceded an onset or a color target, and manipulated set size as a within- or between-subject factor. In four experiments, the original finding of Folk et al. (1992) was replicated only when a fixed set size (four) was used throughout. When both set-size four and eight were used in an experiment, stimulus-driven capture by onset in search of a color target was found even for set-size four displays. These results raise doubts as to the generality of the contingent-orienting hypothesis and help to delineate the boundary conditions on this hypothesis.
\end{abstract}

(c) 2008 Elsevier B.V. All rights reserved.

\section{Introduction}

It has long been recognized that attentional control involves both stimulus-driven and goal-directed components (James, 1890). Recently, the issue of whether and how a task-irrelevant stimulus receives attentional priority in a stimulus-driven fashion has been intensively studied under the subject of attentional capture (e.g., Gibson, 1996; Hillstrom \& Yantis, 1994; Horstmann, 2002; Johnson, Hutchison, \& Trammell Neill, 2001; Rauschenberger \& Yantis, 2001; Remington, Johnston, \& Yantis, 1992; Theeuwes, 1994; Turatto \& Galfano, 2000, 2001; Yantis, 1993; Yantis \& Egeth, 1999). On the one hand, some researchers argue for stimulus-driven attentional capture even when the stimulus does not match with the defining feature of the target (the stimulus-driven orienting hypothesis, e.g., Theeuwes, 1994; Yantis \& Jonides, 1984). On the other hand, other researchers doubt whether purely stimulus-driven capture ever exists and postulate instead that attentional capture is contingent on the attentional control setting adopted by the participant to perform the task (the contingent-orienting hypothesis, Folk, Remington, \& Johnston, 1992).

Studies that support the stimulus-driven orienting hypothesis have mostly used a visual search paradigm. Two indices are used as evidence for attentional capture. The first index is poorer performance when the target is presented along with a task-irrele-

\footnotetext{
* Corresponding author. Tel.: +886 2 33663097; fax: +886 223629909

E-mail address: suling@ntu.edu.tw (S.-L. Yeh).
}

vant distractor. For example, Theeuwes (1994) asked his participants to search for a target that was defined by a particular color, and found longer reaction times (RTs) when there was an onset distractor than when there was no onset distractor. Evidently, the appearance of the onset distractor affects the allocation of attention and thus is detrimental to the detection of the color target. The second index is the near-zero search slope when RT is plotted as a function of set size. For example, Yantis and Jonides (1984) asked their participants to search for a target letter. When the target happened to be an onset (which occurred only at chance level), the RT was relatively independent of the total number of items in the display, suggesting that the onset stimulus captures attention.

Studies that support the contingent orienting hypothesis, on the other hand, usually use a spatial cueing paradigm in which a task-irrelevant cue is presented before the target. RTs to a target appearing at a cued location are compared to those when the location is uncued. The cue is non-informative because it is no more likely that the target location would be the same as the cue than that it would be different from it. Thus, for the task at hand, the best strategy is to ignore the cue and respond to the target as soon as possible. If RT is shorter when the target appears at the cued location than when it appears at the un-cued one (i.e., the validity effect), attentional capture by the cue is inferred. The absence of this validity effect, conversely, indicates that the appearance of the cue does not affect the performance; that is, no attentional capture occurs. 
Folk et al. (1992) used this spatial cueing paradigm and found that attentional capture is contingent on top-down attentional setting for static or dynamic discontinuity. For example, to find a red target letter, a red cue showed the validity effect, but an onset cue did not. In this case, the participant was supposedly set for static discontinuity elicited by the task of searching for a red target among white distractors since this is the property useful in locating the target, and a red cue was able to capture attention because it matches with the property that is critical for the task at hand. The onset cue, in contrast, could not capture attention because the cue property does not match with the attentional set elicited by the behavioral goal. They also tested the condition of a color or an onset cue that preceded an onset target, and the result was also consistent with the contingent orienting hypothesis; that is, only an onset cue (or a motion cue, Folk, Remington, \& Wright, 1994) that signaled the dynamic discontinuity as in the target display captured attention. These findings are important because they suggest that involuntary orienting is in fact contingent on endogenous attentional control setting, and only within the same setting can stimulus salience play a role (Folk et al., 1994).

However, only displays with set-size four were used and they were used throughout the experiments in the series of studies supporting the contingent-orienting hypothesis (e.g., Folk \& Remington, 1998, 1999; Folk et al., 1992, 1994). Hence, it remains unknown whether the results can be generalized to other conditions. There are two reasons to doubt the generalizability of this hypothesis. First, our visual world is full of various numbers of stimuli, and thus using a fixed (and rather small) set size throughout the experiments would lead to the problem of constricted ecological validity. Secondly, previous studies have used a larger set size (e.g., six items, Lamy \& Egeth, 2003) or different set sizes within blocks in an experiment (e.g., 12 and 20 items, Theeuwes, 2004) and found evidence for stimulus-driven attentional capture. Nevertheless, the displays and the paradigms in these studies were different from those used by Folk and colleagues, which preclude a fair comparison if using fixed set size is a problem in the series of studies by Folk and colleagues.

We provide a direct comparison in the current study by using a similar spatial cueing paradigm as in Folk et al. (1992) to test whether the contingent-orienting hypothesis remains true by manipulating set size as a within- or between-subject factor. In Experiment 1, we modified the original design of Folk et al. (1992) by adding a set-size eight condition. In Experiment 2, we further added another distracting color along with the target color so that the color target was no longer a singleton in the target display and thus searching for a singleton was not possible. Experiments 3 and 4 more closely followed the displays and the designs in Folk et al. (1992) to illuminate the boundary conditions on the contingent-orienting hypothesis.

\section{Experiment 1}

In addition to set-size four as used throughout by Folk and colleagues, we added one more set size (eight) in this experiment. If our hypothesis about fixed set size is correct and if attentional capture by onset can be found in this experiment, it would pose a problem for the generalizability of the contingent-orienting hypothesis.

In this experiment, the participants were required to search for and identify a red target, and the target was preceded by either a non-informative onset ${ }^{1}$ cue or color cue. According to the contin-

\footnotetext{
${ }^{1}$ The onset cue was defined by brightening and thickening one of the multiple thin boxes, which may be considered as an old-object onset, rather than a new-object onset. We tested the new-object onset cue in Experiments 3 and 4.
}

gent-orienting hypothesis, only a color cue, not an onset cue, can capture attention under this condition. Note that unlike the experiments in Folk et al. (1992), where the two kinds of cues (color, onset) and the two kinds of targets (color, onset) were crossed, we examined only the capture effect by irrelevant color or onset cues in search of a color target, without testing the capture effect by these two kinds of cues in search of an onset target. This is to keep the number of trials within a reasonable range and adding one more set-size condition has unavoidably doubled the trials, which can be offset by testing one side of the story first. We chose to test first the more likely condition of stimulus-driven attentional capture by onset in search of a color target, due to hints from previous studies that onset seems unique in capturing attention (e.g., Gellatly, Cole, \& Blurton, 1999; Lamy \& Egeth, 2003; Schreij, Owens, \& Theeuwes, 2008; Theeuwes, 1994, 1995; Yantis \& Egeth, 1999; Yantis \& Jonides, 1984). Experiment 4 provides a more comprehensive test by crossing the two kinds of cues and targets.

\subsection{Method}

\subsubsection{Participants}

Thirty-three undergraduates at National Taiwan University participated in this experiment. All had normal or corrected-to-normal vision, and were naïve about the purpose of this experiment.

\subsubsection{Stimuli and design}

The validity effect was used as an index of attentional capture by the cue, following Folk et al. (1992). The design was a threeway factorial design with cue validity (valid, invalid), cue type (onset, color), and set size (four, eight) as within-subject factors. Stimulus displays were controlled by an IBM 486 personal computer and were presented on a $20 \mathrm{in}$. SONY monitor with a refresh rate of $70 \mathrm{~Hz}$. Participants sat at a viewing distance of $60 \mathrm{~cm}$ in a dimly lighted chamber. Each trial contained three kinds of display: the fixation, cue, and target display. A plus sign $\left(0.8^{\circ} \times 0.8^{\circ}\right)$ in gray (CIE $\left.(.302, .302), 1.47 \mathrm{~cd} / \mathrm{m}^{2}\right)$ served as the fixation in each frame throughout the trials. In the fixation display, four or eight thin $\left(0.06^{\circ}\right)$ gray boxes $\left(2.3^{\circ} \times 1.8^{\circ}\right)$ were presented at the circumference of an imaginary circle with a radius of $5.1^{\circ}$. In the set-size four condition, the four boxes were presented at the locations of $0^{\circ}, 90^{\circ}$, $180^{\circ}$, and $270^{\circ}$. In the set-size eight condition, four more boxes were added at the locations of $45^{\circ}, 135^{\circ}, 225^{\circ}$, and $315^{\circ}$. The cues were non-informative as to the target location, being at the chance level of $25 \%$ and $12.5 \%$ in set-size four and eight conditions, respectively. For the two kinds of cue display, the onset cue was a thick white box (CIE $(.291, .300), 7.32 \mathrm{~cd} / \mathrm{m}^{2}$ ) with a width of $0.22^{\circ}$ among three or seven thin gray boxes. The color cue was one red box (CIE (.612, .345)) among three or seven white boxes, with all boxes having the same width $\left(0.22^{\circ}\right)$ and luminance $\left(7.32 \mathrm{~cd} / \mathrm{m}^{2}\right)$. In the target display, four or eight letters $\left(1.3^{\circ} \times 0.8^{\circ}\right)$ appeared in each of the gray boxes. One of the letters, the target letter $\mathrm{H}$ or $\mathrm{U}$, was red. The other three or seven were white letters $\mathrm{P}, \mathrm{E}$, and $\mathrm{S}$, each appearing once for set-size four and at least twice for set-size eight.

\subsubsection{Procedure}

In each trial, the sequence of displays was as follows (Fig. 1): fixation $(500 \mathrm{~ms})$, cue $(100 \mathrm{~ms})$, fixation $(100 \mathrm{~ms})$, target (200 ms), and fixation (until response). Except for the first, each trial started immediately after the response to the preceding trial. The target letter was always presented and was equally likely to be an $\mathrm{H}$ or a $U$. The participant was required to press the left shift key if the target was an $\mathrm{H}$, and the right shift key if it was a U. The participants were informed that within each set size the location where the cue appeared was irrelevant to the target. They were instructed to ignore the cues, to maintain fixation throughout each 


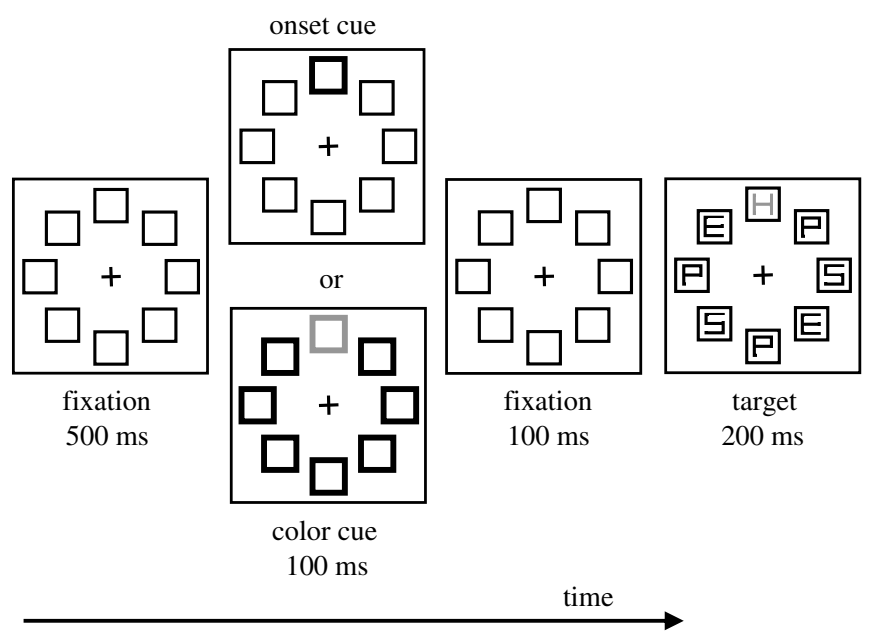

Fig. 1. The display and procedure used in Experiment 1. The outlines of the boxes and the fixation plus are in dark gray. The thick black boxes in the cue display shown here were white in the experiment. The thick gray box and the gray target letter were red, and the other letters in the target display were white (not-to-scale). The last fixation frame is not shown here.

trial, and to respond as quickly and yet accurately as possible. Feedback (a beep sound) was given whenever an incorrect response was made.

Each of the two cue types (color or onset) comprised half of the trials, and their presentation order was randomly assigned within each set-size condition (four or eight). The two set-size conditions were run in six blocks (64 trials each) alternately, always starting with set size 8 . Thirty-two practice trials preceded the experimental 384 trials. The participants took short self-paced breaks between experimental blocks.

\subsection{Results and discussion}

RTs deviating from three times the standard deviation were excluded from further analysis in all the experiments reported, and in no experiment did these removed trials exceed $2 \%(M=1.43 \%)$.
Results of this experiment are shown in Fig. 2. The three-way repeated measures ANOVA showed the main effects of cue validity $[F(1,32)=63.09, \quad M S e=52162.48, \quad p<.0001]$ and cue type $[F(1,32)=22.27$, MSe $=9036.62, p<.0001]$, as well as the twoway interactions of cue validity and set size $[F(1,32)=9.78$, $\mathrm{MSe}=3831.42, p<.01]$, cue validity and cue type $[F(1,32)=10.49$, $\mathrm{MSe}=4835.35, p<.01]$, and cue type and set size $[F(1,32)=6.00$, $\mathrm{MSe}=1397.73, p<.02$ ] . Tukey's test revealed significant validity effects for color cues and onset cues in both the set size four and eight conditions. To provide further information, the validity effects were subjected to a two-way ANOVA with the factors of cue type and set size. Results showed that the validity effect was larger for color cues than for onset cues $[F(1,32)=13.68$, MSe $=12362.14, p<.001]$ and larger for set size eight than for set-size four $[F(1,32)=12.63$, MSe $=9938.25, p<.01]$. Analysis of error rates showed neither main effects nor interactions, indicating no speed-accuracy trade-off.

Contrary to the prediction of the contingent-orienting hypothesis, when searching for a color target both irrelevant color and onset cues captured attention with set-size four and eight. The presentation of two kinds of set size has never been used in the series of studies by Folk and colleagues (e.g., Folk \& Remington, 1998, 1999; Folk et al. 1992, 1994), and the fact that they always use the same set-size four displays evidently limits the generalization range of the contingent-orienting hypothesis. When more than one set size displays were used in this experiment, attentional capture by the irrelevant onsets that do not match the behavioral goal of searching for a static (color) discontinuity was obtained.

This statement, however, may be qualified by raising the doubt that it is possible that our participants may have adopted a singleton search mode to find the color singleton target (Bacon \& Egeth, 1994). Given that the onset cue was also a singleton in the cue display, the finding of attentional capture by onset is still in line with the contingent-orienting hypothesis, because this capture is contingent on the top-down control setting for a singleton, rather than contingent on bottom-up stimulus factors. We test whether attentional capture by onset still occurs by excluding the possibility of participants' adopting a singleton search mode in the next experiment.

\section{Attentional set for color}

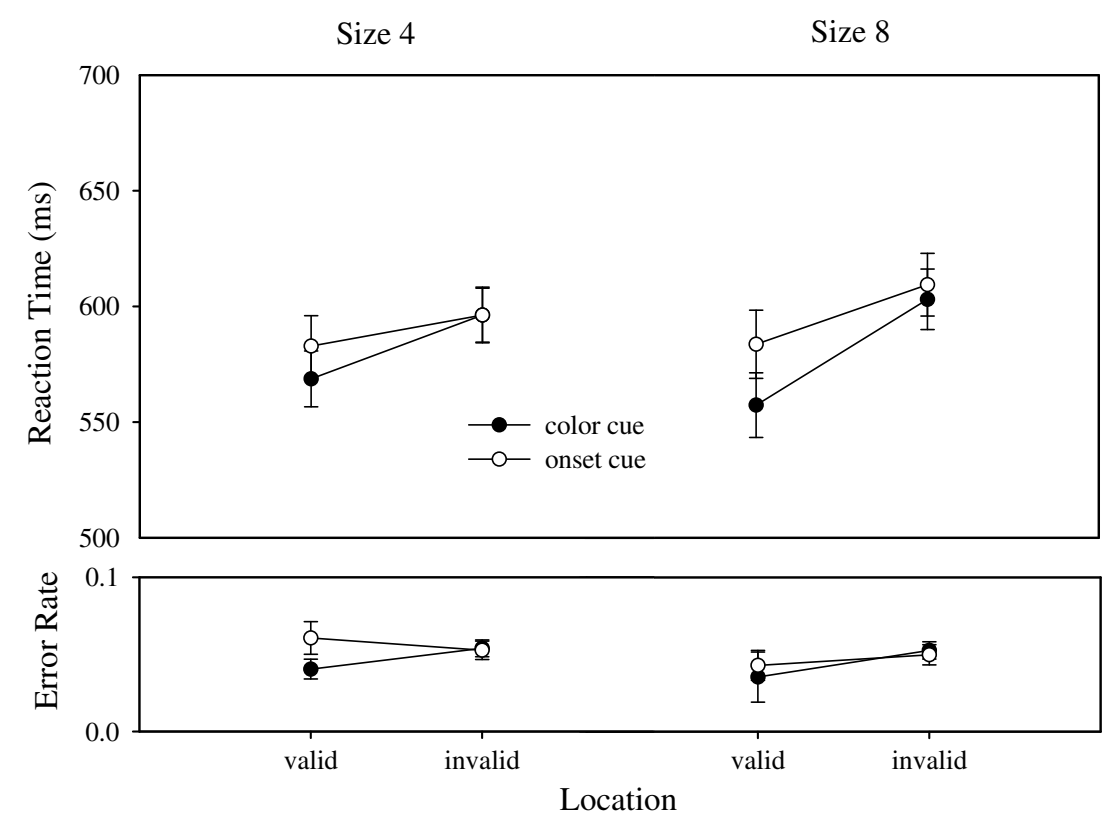

Fig. 2. Mean reaction times and error rates for target identification in Experiment 1. 


\section{Experiment 2}

To prevent participants from adopting a singleton detection mode to perform the task, a necessary condition was to make the target a non-singleton. To our knowledge, this has not been done when different set sizes are performed in the same experiment, although it has been examined with fixed set-size conditions (e.g., Folk \& Remington, 1998; Lamy \& Egeth, 2003; Schreij et al., 2008). By making the target display with two colors, red and green, we ensured that the participants could no longer adopt the strategy of searching for a singleton. If the onset cue cannot capture attention under this condition, then the capture effect obtained in Experiment 1 could well be attributed to the singleton search strategy adopted by the participants. If, however, the onset cue can capture attention even when the participants cannot adopt a singleton search mode, the evidence for stimulus-driven attentional capture is stronger.

\subsection{Method}

\subsubsection{Participants}

Another group of 31 undergraduates as described in Experiment 1 participated in this experiment.

\subsubsection{Stimuli, design, and procedure}

Stimuli, design, and procedure were the same as in Experiment 1 , except that in the target display, one of the non-target white letters was replaced by a green one. The chance of which letter would be green was equally distributed among the non-target letters. There were 48 trials in each block, and thus the total number of trials was 288 .

\subsection{Results and discussion}

Fig. 3 shows the results. The main effects of cue validity $[F(1,30)=81.00, \quad M S e=77601.93, \quad p<.0001]$ and cue type $[F(1,30)=33.90, \mathrm{MSe}=17889.59, p<.0001]$ were significant, as was the two-way interaction of cue validity and cue type
$[F(1,30)=53.83$, MSe $=27138.13, p<.0001]$. Tukey's test showed significant validity effects for both color and onset cues, in both set-size four and eight conditions. A larger validity effect was found for color cues than for onset cues $[F(1,30)=53.83$, $\mathrm{MSe}=54278.61, p<.0001]$. Analyses of error rates showed that the main effect of cue validity $[F(1,30)=16.04, \quad M S e=0.02$, $p<.001]$ and the interaction of cue type and set size $[F(1,30)=4.49$, MSe $=0.008, p<.05]$ were significant. Error rates were lower for onset cues than for color cues only in the set-size four condition $[F(1,60)=5.75$, MSe $=0.012, p<.02]$. Speed-accuracy trade-off does not seem to be a problem here.

Thus, the onset cue could still capture attention in both set-size conditions in the non-singleton target search display. Since in this case the singleton detection mode could not be adopted, attentional capture by onset cannot be attributed to such a detection mode. This raises further doubts about the generality of the contingent-orienting hypothesis.

\section{Experiment 3}

We have shown in the previous two experiments that an onset cue could capture attention even when the participants were asked to look for a color target. It may still be argued that the onset cue we used was not a real onset cue because, unlike Folk et al. (1992), who used four dots around one placeholder box as the onset cue, we used a brightened and thickened placeholder box. Thus, the onset cue we used in Experiments 1 and 2 may have confounded the properties of onset and brightness, and the box could be considered an old object rather than a new one. However, this should not in fact be a problem because, if so, a new object should be expected to capture attention even more strongly than an old one. Nevertheless, to ensure that the attentional capture by onset we observed in previous experiments was not caused by the old-object onsets we used, in this experiment we changed the onset cue to be the same as in Folk et al. (1992) to see whether our results could still be replicated. We also changed the SOAs and the target display to follow more closely those used in Folk et al. (1992).

\section{Attentional set for color}

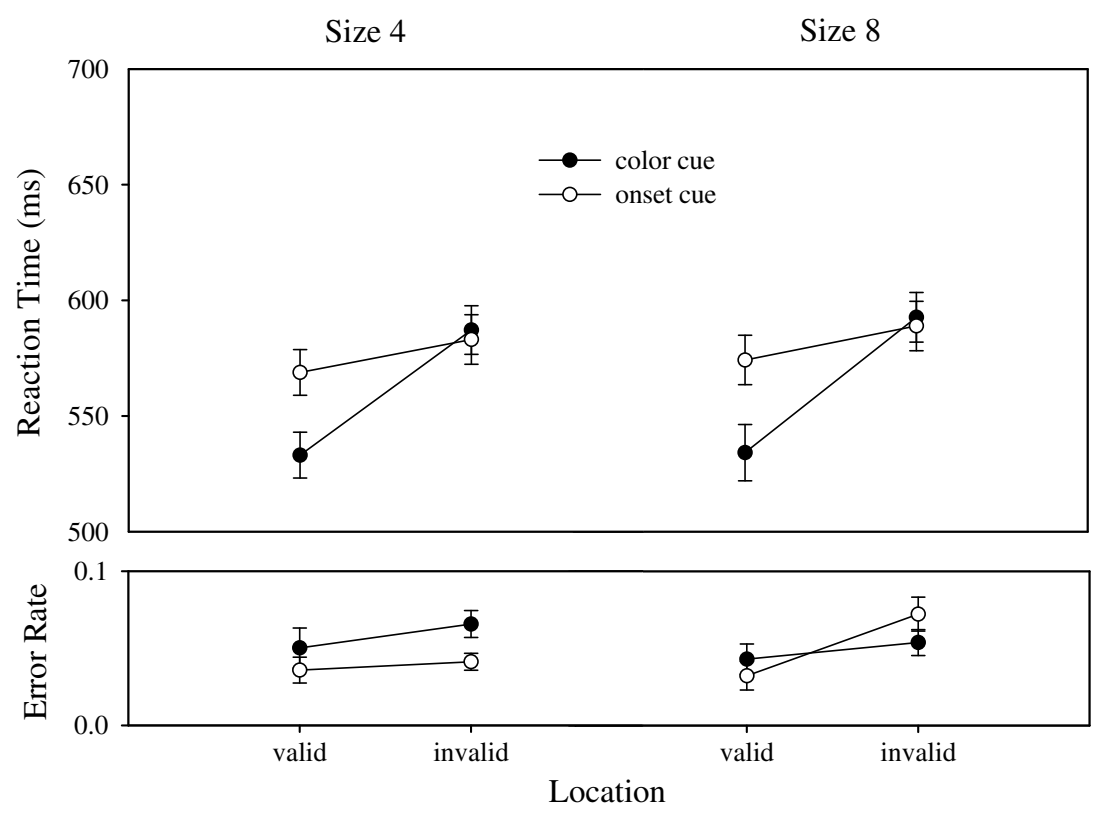

Fig. 3. Mean reaction times and error rates for target identification in Experiment 2. 


\subsection{Method}

\subsubsection{Participants}

Fourteen undergraduates as described in Experiment 1 participated in this experiment.

\subsubsection{Stimuli and design}

The same design as in Experiment 1 was used, except for the following. Stimulus displays were presented on a 21 -in. EIZO monitor (Flex Scan T966), with a refresh rate of $60 \mathrm{~Hz}$. Participants sat at a viewing distance of $54 \mathrm{~cm}$ in a dimly lighted chamber. Each trial consisted of three kinds of display: the fixation, cue, and target displays (Fig. 4). A dot $\left(2.1^{\circ} \times 2.1^{\circ}\right)$ in gray $(R G B=95,95,95)$ served as the fixation point throughout the trials. In the fixation

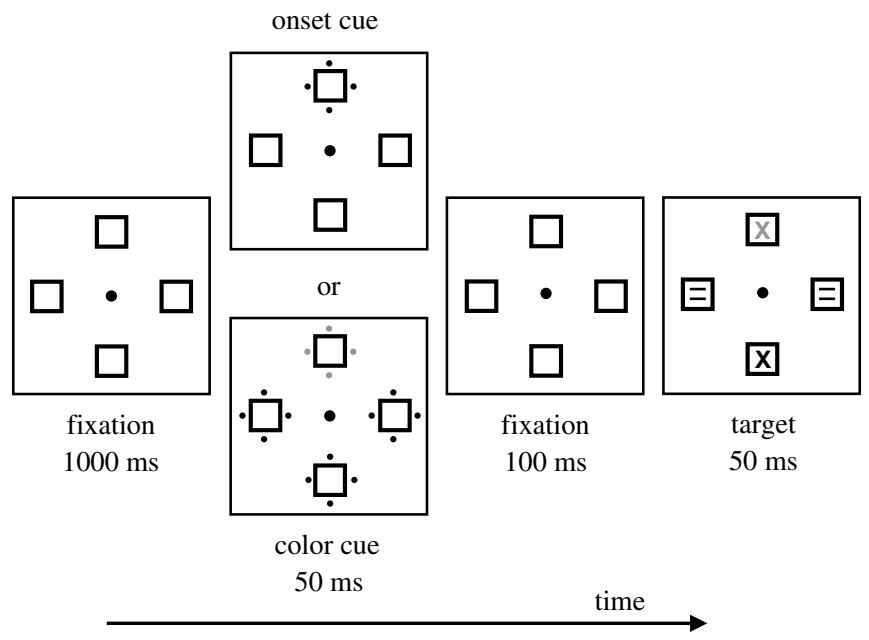

Fig. 4. The display and procedure used in Experiment 3 (not-to-scale). The outlines of the boxes and the fixation dot were in dark gray. The four black small dots surrounding the box in the cue display shown here were white in the experiment. The gray dots and the gray sign were red, and the other signs in the target display were white. display, four or eight thin $\left(0.8^{\circ}\right)$ gray boxes $\left(12.5^{\circ} \times 12.5^{\circ}\right)$ were presented at the circumference of an imaginary circle with a radius of $37.5^{\circ}$.

In the onset cue display, one of the four or eight gray thin boxes was surrounded by four white dots $\left(1.7^{\circ} \times 1.7^{\circ}\right)$ at the position of $0^{\circ}, 90^{\circ}, 180^{\circ}$, and $270^{\circ}$. In the color cue display, one of the four or eight gray thin boxes was surrounded by four red $(\mathrm{RGB}=218,37$, 29) dots, while the other boxes were surrounded by white dots. In the target display, four or eight different signs $\left(5^{\circ} \times 5^{\circ}\right)$ were presented in each of the gray boxes. One of the signs was red and the others were white. The signs were either an " $x$ " or an " = ", presented within the boxes.

\subsubsection{Procedure}

In each trial, the sequence of displays was as follows: fixation (1000 ms), cue (50 ms), fixation (100 ms), and target (50 ms). The red target was always presented and was equally likely to be an " $x$ " or an " =". The participant was required to press the " $Z$ " if the target was an " $\times$ ", and the "/" if it was an " = ". The two set size conditions were separated in two blocks and the order was counterbalanced. When the set size was four, there were 64 onset cue trials and 64 color cue trials. Within each cue-type condition, there were 16 same-location trials and 48 different-location trials. When the set size was eight, there were 128 onset cue trials and 128 color cue trials. Within each cue-type condition, there were 16 samelocation trials and 112 different-location trials. Half of the trials corresponded to the response type " $\times$ " and the other half to "=" Eight practice trials preceded the experimental trials. Participants pressed the spacebar to initiate each trial. Other details were the same as in Experiment 1.

\subsection{Results and discussion}

Fig. 5 shows the results. The main effects of cue validity $[F(1,13)=170.93, \quad$ MSe $=45558.38, \quad p<.0001]$ and cue type $[F(1,13)=37.78, \quad M S e=4067.12, p<.0001]$ were significant, as was the two-way interaction of cue validity and cue type $[F(1,13)=17.81, \quad M S e=8540.04, p<.001]$. Again, Tukey's test

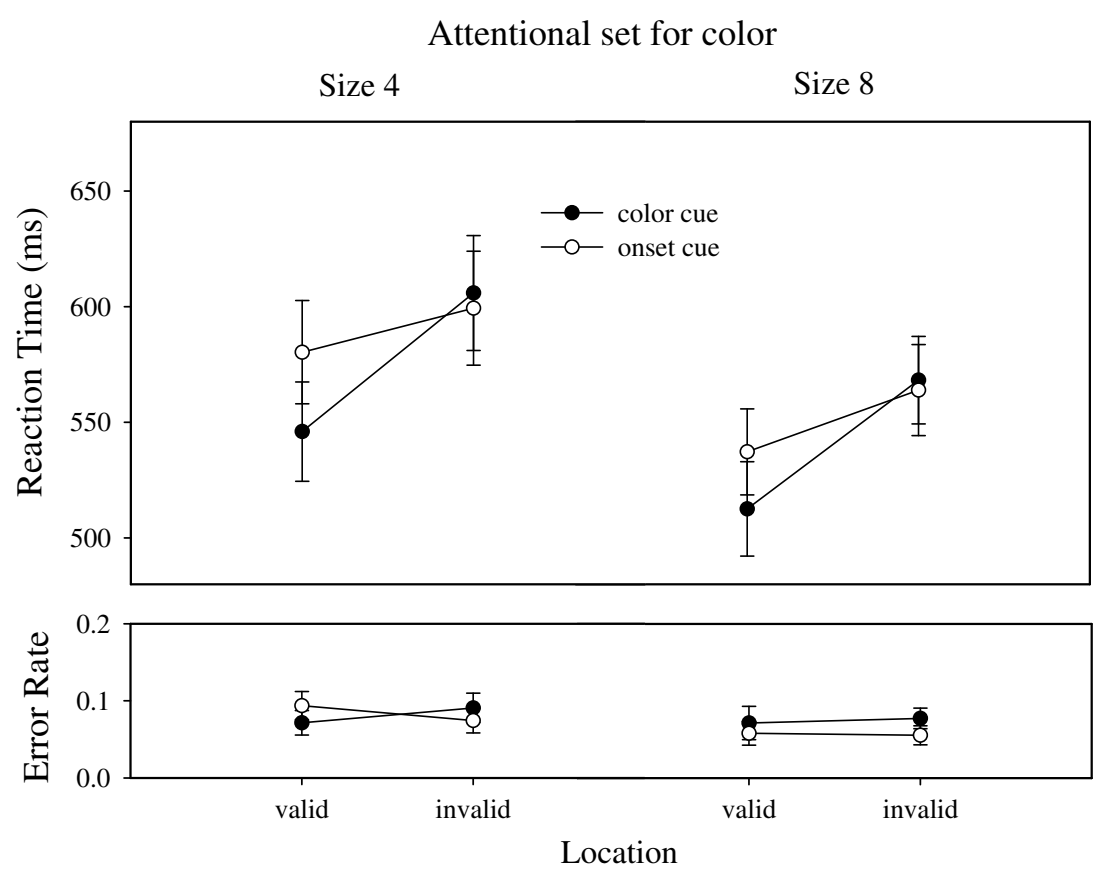

Fig. 5. Mean reaction times and error rates for target identification in Experiment 3. 
showed significant validity effects for both color and onset cues, in both set size four and eight conditions. A larger validity effect was found for color cues than for onset cues $[F(1,13)=17.81$, MSe $=17080.42, p<.01]$. Analysis of error rates showed neither main effects nor interactions, indicating no speed-accuracy tradeoff.

We still found attentional capture by irrelevant onset in both set-size four and set-size eight conditions, even with identical displays and SOAs as used in Folk et al. (1992). In Experiments 1 and 2 , we had adopted the onset cue used by Folk and Remington (1999); in this experiment we used the four-dot onset cue as in Folk et al. (1992). Very similar result patterns were obtained, using the two kinds of onset cues. In fact, Folk and Remington (1999) did not treat the two kinds of onset cue differently and the results they obtained for the two kinds of cue did not differ either.

One puzzle still remains. Why, with a very similar design to Folk et al. (1992), did we still find attentional capture by onset with setsize four? Two factors may have contributed to the different results obtained here from those in Folk et al. (1992). First, only color targets were used in this experiment to examine the capture effect caused by color and onset cues, whereas in Folk et al. (1992) both color and onset targets were used. Secondly, in this and the previous two experiments, the participants conducted both set-size four and eight conditions, and the participants in Folk et al. (1992) only conducted set-size four conditions throughout the experiment. Working with fixed set size throughout may have led them to focus more narrowly on the setting for the defining feature of the target, and thus stimulus-driven capture would have been better suppressed. In the next experiment, we followed the displays and designs in Folk et al. (1992) even more closely by eliminating these differences in order to test this hypothesis.

\section{Experiment 4}

Separate experiments were conducted using the two set-size conditions, with two groups of participants. In addition to changing the manipulation of set size as a between-subject factor, we added an onset target condition, making a 2 (cue: onset or color) $\times 2$ (target: onset or color) factorial design, just as in Folk et al. (1992). In this way, the set-size four condition was now identical to that in Folk et al. (1992), and we should expect to find replication of their results; namely, only the cue that matched the defining feature of the target would capture attention. By making the set-size eight condition comparable to the set-size four condition as in Folk et al. (1992), the boundary conditions on the contingent-orienting hypothesis can be better illuminated by the contrast pattern, if it exists, between the two set-size conditions.

\subsection{Method}

\subsubsection{Participants}

Thirty four undergraduates as described in Experiment 1 were tested. Half were assigned to the set-size four condition and half to the set-size eight condition.

\subsubsection{Stimuli, design, and procedure}

The stimuli, design, and procedure were the same as for Experiment 3, except that set size was now a between-subject factor and an onset target condition was added. In the onset target display, only one white sign (either an " $x$ " or an " =") appeared in one of the four or eight gray boxes. For each set size, the two target-type conditions were separated in two blocks with a random presentation order. In the set size four condition, there were 128 trials for each target-type condition. Within each target type condition, there were 64 trials for each cue type condition, which consisted of 16 same-location trials and 48 different-location trials. In the set-size eight condition, there were 256 trials for each target-type condition. Within each target-type condition, there were 128 trials for each cue-type condition, which consisted of 16 same-location trials and 112 different-location trials. Four practice trials preceded the experimental trials in each target-type condition.

\subsection{Results and discussion}

Fig. 6 and Fig. 7 show the results for set-size four and eight conditions, respectively. Separate ANOVAs with the factors of cue validity, cue type, and target type were conducted for the two set-size conditions.

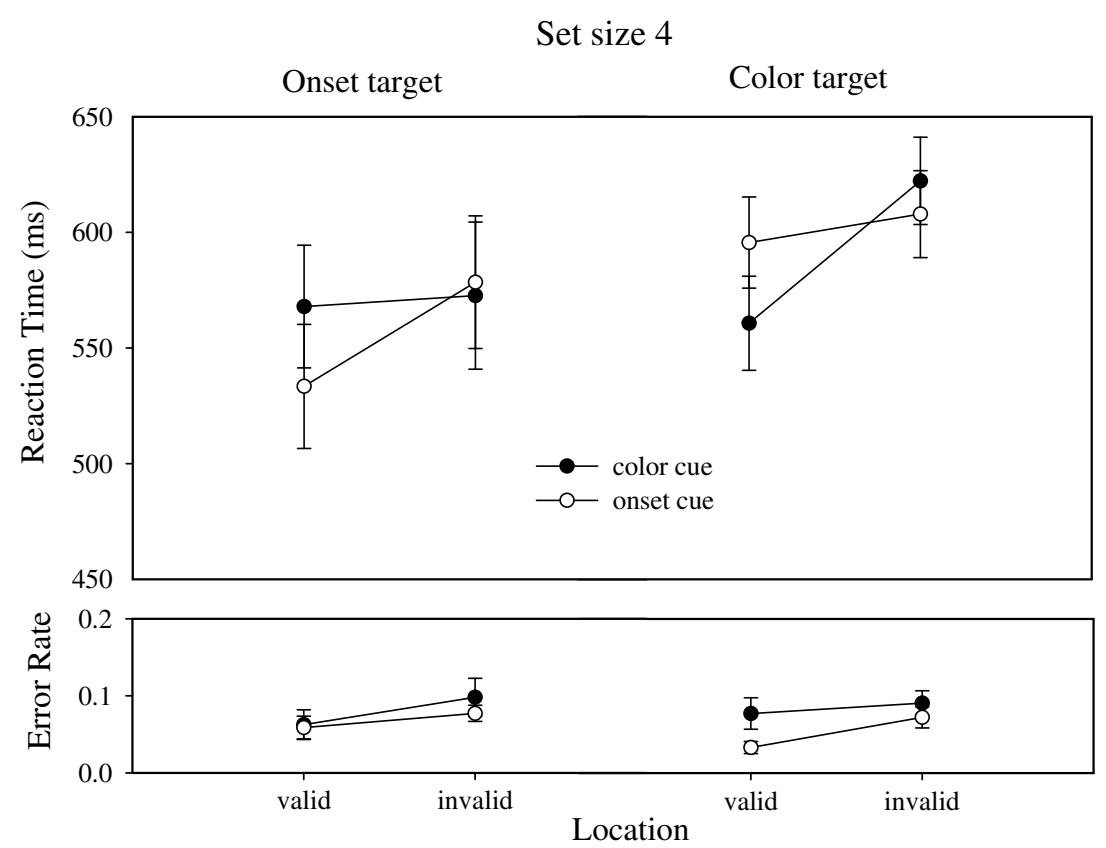

Fig. 6. Mean reaction times and error rates for target identification in the set-size four condition in Experiment 4. 
Set size 8

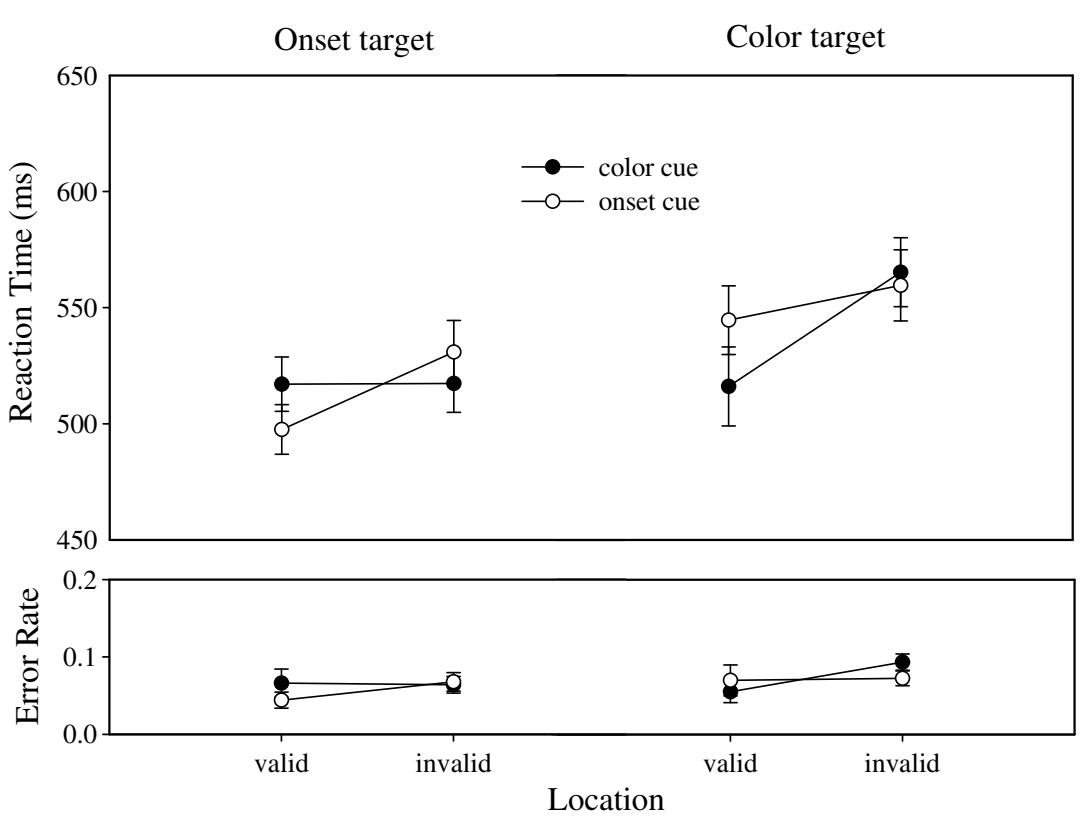

Fig. 7. Mean reaction times and error rates for target identification in the set-size eight condition in Experiment 4.

\subsubsection{Set-size four}

The main effect of cue validity $[F(1,16)=35.07, \mathrm{MSe}=32496.30$, $p<.0001]$, the two-way interaction of cue type and target type $[F(1,16)=5.24, \mathrm{MSe}=5147.31, p<.04]$, and the three-way interaction of cue validity, cue type, and target type $[F(1,16)=18.06$, $\mathrm{MSe}=17064.77, p<.001]$ were significant. In the onset-target condition, the validity effect was found for onset cues $[F(1,64)=24.84$, $\mathrm{MSe}=17257.08, p<.0001]$ but not for color cues $[F(1,64)=0.27$, $\mathrm{MSe}=190.55, p>.6]$. In contrast, in the color-target condition, the validity effect was found for color cues $[F(1,64)=46.40$, $\mathrm{MSe}=32232.20, p<.0001]$ but not for onset cues $[F(1,64)=1.85$, $\mathrm{MSe}=1283.88, p>.1]$. Analysis of error rates showed only the main effect of cue validity $[F(1,16)=5.84$, MSe $=0.024, p<.03]$, indicating no speed-accuracy trade-off.

\subsubsection{Set-size eight}

The main effects of cue validity $[F(1,16)=63.74$, $\mathrm{MSe}=20309.15, \quad p<.0001]$ and target type $[F(1,16)=9.86$, MSe $=32022.56, p<.01]$ were significant, as were the two-way interactions of cue type and target type $[F(1,16)=6.27$, MSe $=1776.85, \quad p<.03]$, cue validity and target type $[F(1,16)=5.57, \mathrm{MSe}=1989.61, p<.04]$, and the three-way interaction of cue validity, cue type, and target type $[F(1,16)=23.96$, MSe $=9629.12, p<.001]$. The validity effect was found in onset targets for onset cues $[F(1,64)=27.42$, MSe $=9444.89, p<.0001]$ but not for color cues $[F(1,64)=0.002$, MSe $=0.52, p>.9]$, whereas it was found in color targets for both onset and color cues $[F(1,64)=5.53, \quad \mathrm{MSe}=1906.36, \quad p<.03 \quad$ and $F(1,64)=59.74$, $\mathrm{MSe}=20578.88, p<.0001$, respectively]. Analysis of error rates showed only the main effect of cue validity $[F(1,16)=6,33$, MSe $=0.008, p<.03$ ], indicating no speed-accuracy trade-off.

\subsubsection{Comparison of the validity effect}

The validity effects in each set-size condition were subjected to a two-way ANOVA with the factors of cue type and target type. In the set-size four condition, the two-way interaction of cue type and target type was significant $[F(1,16)=18.06$, MSe $=34130.43$, $p<.001$ ]. In the set-size eight condition, the main effect of target type $[F(1,16)=5.57, \quad M S e=3978.00, p<.04]$ and the two-way interaction $[F(1,16)=23.96$, MSe $=19260.25, p<.001]$ were significant. In both set-size conditions, Tukey's test indicated a larger validity effect for onset cues than for color cues in the onset-target condition, and for color cues than for onset cues in the color-target condition. Also, the validity effect of the onset cue was larger when it was followed by onset target than by color target; and it was larger when the color cue was followed by color target than by onset target.

Thus, we have replicated the results of Folk et al. (1992) in that when the participants conducted set-size four trials throughout the experiment only contingent capture was observed: the onset cue failed to capture attention when the target was defined by color, as did the color cue when the target was defined by onset. However, when they conducted set-size eight trials throughout the experiment, stimulus-driven capture was observed with an onset cue in search of a color target, as we have observed in the previous three experiments. Note that the results for set-size eight are asymmetrical: the onset cue captured attention regardless of target type, whereas the color cue captured attention only in search of color target but not of onset target, and the latter is in fact consistent with the contingent capture hypothesis. Taken together, these findings suggest that the contingent-orienting hypothesis has limited generalizability when the irrelevant stimulus is an onset, which appears to be special in that it can capture attention in a stimulus-driven fashion.

\section{General discussion}

Our results in the four experiments reported here not only raise doubts as to the generality of the contingent-orienting hypothesis, but also help to establish boundary conditions on it. We used a spatial-cueing paradigm similar to that in Folk et al. (1992) by presenting a non-informative color or onset cue before a color target (Experiments 1-4) or an onset target (Experiment 4). When setsizes four and eight were within-subject factors in the color target conditions (Experiments 1-3), both the color cue and the onset cue captured attention in both set-size conditions. When the two set- 
size conditions were conducted separately by different groups of participants as a between-subject factor (Experiment 4), the results of Folk et al. (1992) were replicated in the set-size four condition and for the color cue in the set-size eight condition. For the onset cue in the set-size eight condition, however, stimulus-driven capture that is not contingent on top-down control setting was obtained, even with designs (save for set size) almost identical to those used in Folk et al. (1992).

These findings support our hypothesis that the contingent-orienting hypothesis has restricted gereralizability when the supporting evidence comes only from studies using a fixed and rather small set size (four) throughout (e.g., Folk \& Remington, 1998, 1999; Folk et al., 1992, 1994). The replication of contingent capture with set-size four in our Experiment 4 is important because it demonstrates that with our own experimental setup, the results of Folk et al. (1992) can be replicated. However, in other onset-cue colortarget conditions (e.g., old-object onset or new-object onset, singleton color or non-singleton color target, and set-size four or eight), the irrelevant onsets captured attention. As we proposed, facing with fixed and rather small set size throughout the experiment facilitates narrower setting which might better suppress bottom-up stimulus factors. When different set sizes or larger set sizes were used, just as what would be encountered in daily visual world, attentional capture by irrelevant onsets that do not match the top-down control settings is still possible. These results are consistent with those of the previous studies using different set sizes in an experiment (e.g., Theeuwes, 2004) or set sizes larger than four (e.g., Lamy \& Egeth, 2003), despite differences in designs and displays. Together with the asymmetrical results found with irrelevant onset and color cues in the set-size eight condition in Experiment 4, we provide one more piece of evidence supporting the view that onset is special in capturing attention (Franconeri, Simons, \& Junge, 2004; Gellatly et al., 1999; Jonides \& Yantis, 1988; Lamy \& Egeth, 2003; Schreij et al., 2008; Theeuwes, 1995; Yantis \& Egeth, 1999; Yantis \& Jonides, 1984), perhaps due to its transient property in which our visual system is extremely sensitive to (Todd \& Gelder, 1979). When the static field contains denser items or varied number of items, the transient change has higher signal-tonoise ratio and thus attracts attention more easily than when it appears among a small, fixed, static field.

Moreover, the attentional capture by a task-irrelevant onset that we found with both set-size four and eight when a feature search mode was assured (Experiment 2) challenges the strong version of the contingent-orienting hypothesis, since there is no reason to expect this if attentional set alone determines the capture effect. Lamy and Egeth (2003) demonstrated that onset can capture attention regardless of whether singleton detection mode or feature search mode is used. They used set-sizes four and six. However, their color target was defined by a color circle surrounding the target character, a display more similar to Theeuwes' than to Folk's. We have, on the one hand, replicated the absence of attentional capture by onset in Folk et al. (1992, 1994): when the red target was presented as the only color item in the target display (Experiment 4, set size four), presumably a singleton detection mode was favored (Bacon \& Egeth, 1994). On the other hand, we have obtained results consistent with those in Schreij et al. (2008) and Lamy and Egeth (2003) by showing the presence of attentional capture by onset when, presumably, only the feature search mode was allowed (Experiment 2). Combining these findings shows that distinguishing between singleton detection mode and feature search mode (Bacon \& Egeth, 1994; Lamy \& Egeth, 2003) may not adequately account for the current result patterns. Our results thus add to the emergent number of studies questioning the usefulness of the distinction between singleton detection mode and feature search mode (e.g., Lamy, Bar-Anan, Egeth, \& Carmel, 2006; Schreij et al., 2008; Theeuwes, 2004; Theeuwes \& van der Burg, 2008).
In all the color target conditions that we tested, we found a larger capture effect with color cues than with onset cues, indicating that both bottom-up and top-down factors played a role. The validity effect of the onset cue suggests the role of bottom-up factors, which is offset by the top-down influence of searching for a color target. In the same vein, a larger capture effect was also found when the onset cue preceded an onset target, compared to that when it preceded a color target. These provide some support for the contingent-capture hypothesis. Even though the onset-capture effect found here is not completely stimulus-driven, it is not critical to the generality issue raised here either. Note that while we raise doubts as to the generality of the contingent-orienting hypothesis, we do not object to its central concept, that top-down control modulates attentional capture. It is the strong version of this hypothesis that top-down control alone determines the attentional capture that is questioned. We think that attentional capture should not be considered as either contingent on control settings or stimulus-driven, but, rather, dependent on other factors which affect the relative weighting of the top-down and bottom-up components of attentional orienting. We have demonstrated in this study that whether fixed set size used throughout the experiment is on such factor.

In conclusion, our unique contribution in this study is to clarifing the boundary conditions on the contingent-orienting hypothesis, and the results from the participant's having seen displays with different set sizes illustrate one example that does not support this hypothesis. Viewing different set sizes or larger set sizes in an experiment may contribute to the higher likelihood of stimulus-driven capture by onsets, and these factors are more similar to real-world situations than small and constant set sizes used in laboratories. Even under the control of attentional setting, stimulus strength can still exert its effect in the capturing of attention when conditions allow.

\section{Acknowledgement}

This research was supported by grants from National Science Council in Taiwan (NSC93-2752-H-002-008-PAE and NSC952413-H-002-020).

\section{References}

Bacon, W. F., \& Egeth, H. E. (1994). Overriding stimulus-driven attentional capture Perception \& Psychophysics, 55, 485-496.

Folk, C. L., \& Remington, R. (1998). Selectivity in distraction by irrelevant featural singletons: evidence for two forms of attentional capture. Journal of Experimental Psychology: Human Perception and Performance, 24, 847-858.

Folk, C. L., \& Remington, R. (1999). Can new objects override attentional control settings? Perception \& Psychophysics, 61, 727-739.

Folk, C. L., Remington, R. W., \& Johnston, J. C. (1992). Involuntary covert orienting is contingent on attentional control settings. Journal of Experimental Psychology: Human Perception and Performance, 18, 1030-1044.

Folk, C. L., Remington, R. W., \& Wright, J. H. (1994). The structure of attentional control: contingent attentional capture by apparent motion, abrupt onset, and color. Journal of Experimental Psychology: Human Perception and Performance, 20 317-329.

Franconeri, S. L., Simons, D. J., \& Junge, J. A. (2004). Searching for stimulus-driven shiftsof attention. Psychonomic Bulletin E Review, 11, 876-881.

Gellatly, A., Cole, G., \& Blurton, A. (1999). Do equiluminant object onsets capture visual attention? Journal of Experimental Psychology: Human Perception and Performance, 25, 1609-1624.

Gibson, B. S. (1996). Visual quality and attentional capture: A challenge to the special role of abrupt onsets. Journal of Experimental Psychology: Human Perception and Performance, 22, 1496-1504.

Hillstrom, A. P., \& Yantis, S. (1994). Visual motion and attentional capture. Perception E' Psychophysics, 55, 399-411.

Horstmann, G. (2002). Evidence for attentional capture by a surprising color singleton in visual search. Psychological Science, 13, 499-505.

James, W. (1890). Principles of psychology. New York: Holt.

Johnson, J. D., Hutchison, K. A., \& Trammell Neill, W. (2001). Attentional capture by irrelevant color singletons. Journal of Experimental Psychology: Human Perception and Performance, 27, 841-847.

Jonides, J., \& Yantis, S. (1988). Uniqueness of abrupt visual onset in capturing attention. Perception \& Psychophysics, 43, 346-354. 
Lamy, D., Bar-Anan, Y., Egeth, H. E., \& Carmel, T. (2006). Effects of top-down guidance and singleton priming on visual search. Psychonomic Bulletin E'Review, 13, 287-293.

Lamy, D., \& Egeth, H. E. (2003). Attentional capture in singleton-detection and feature-search modes. Journal of Experimental Psychology: Human Perception and Performance, 29, 1003-1020.

Rauschenberger, R., \& Yantis, S. (2001). Attentional capture by globally defined objects. Perception \&' Psychophysics, 63, 1250-1261.

Remington, R. W., Johnston, J. C., \& Yantis, S. (1992). Involuntary attentional capture by abrupt onsets. Perception \& Psychophysics, 51, 279-290.

Schreij, D., Owens, C., \& Theeuwes, J. (2008). Abrupt onsets capture attention independent of top-down control settings. Perception \& Psychophysics, 70, 208-218.

Theeuwes, J. (1994). Stimulus-driven capture and attentional set: Selective search for color and visual abrupt onsets. Journal of Experimental Psychology: Human Perception and Performance, 20, 799-806.

Theeuwes, J. (1995). Abrupt luminance change pops out; abrupt color change does not. Perception \& Psychophysics, 57, 637-644.

Theeuwes, J. (2004). Top-down search strategies cannot override attentional capture. Psychonomic Bulletin E' Review, 11, 65-70.
Theeuwes, J., \& van der Burg, E. (2008). The role of cueing in attentional capture. Visual Cognition, 16, 232-247.

Todd, J. T., \& Gelder, P. V. (1979). Implications of a transient-sustained dichotomy for the measurement of human performance. Journal of Experimental Psychology: Human Perception and Performance, 5, 625-638.

Turatto, M., \& Galfano, G. (2000). Color, form and luminance capture attention in visual search. Vision Research, 40, 1639-1643.

Turatto, M., \& Galfano, G. (2001). Attentional capture by color without any relevant attentional set. Perception \& Psychophysics, 63, 286-297.

Yantis, S. (1993). Stimulus-driven attentional capture and attentional control settings. Journal of Experimental Psychology: Human Perception and Performance, 19, 676-681.

Yantis, S., \& Egeth, H. E. (1999). On the distinction between visual salience and stimulus-driven attentional capture. Journal of Experimental Psychology: Human Perception and Performance, 25, 661-676.

Yantis, S., \& Jonides, J. (1984). Abrupt visual onsets and selective attention: Evidence from visual search. Journal of Experimental Psychology: Human Perception and Performance, 10, 601-621. 